\title{
Regenerative Shock Absorber: Research Review
}

\author{
Dr. Seema Tiwari \\ Dept. of ASGE, \\ Army Institute of Technology,Pune. \\ Dighi Hills,Alandi Road,Pune.(411015).
}

\author{
Manish Kumar Singh \\ Dept. of ASGE, \\ Army Institute of Technology,Pune. \\ Dighi Hills,Alandi Road,Pune.(411015).
}

\author{
Amit Kumar \\ Dept. of ASGE, \\ Army Institute of Technology,Pune. \\ Dighi Hills,Alandi Road,Pune.(411015).
}

\begin{abstract}
Sustainable power source advancements, especially in electric vehicles $(\mathrm{EVs})$, have gotten noteworthy consideration in recent years. Because of the anomalies out and about surfaces our vehicles experience shocks. The customary suspension framework in our vehicles lessen these shocks and convert this mechanical vibrational energy into heat. In this procedure a lot of fuel energy is squandered which can be recouped utilizing a regenerative suspension framework. A regenerative suspension framework can successfully retain these vibrations just as lessen the measure of energy lost to the encompassing. This paper audits the current research on the regenerative shock absorbers. It initially examines about the energy dispersal from the vehicles and afterward the capability of recouping this scattered energy utilizing a regenerative shock absorber. It additionally audits the different innovative work done on the regenerative shock absorber.
\end{abstract}

Keywords-Electromagnetic actuator, regenerative shock absorber, structure, vehicle suspension system, vibration energy.

\section{INTRODUCTION}

These days because of fast development and advancement in innovation and ascend in the ways of life the quantity of car vehicles on street is likewise expanding quickly. This has prompted immense increment in energy utilization, squander creation and different issues like environmental pollution. Thus, we should discover approaches to preserve energy and non-regular sources to deliver it. As of late, EVs have picked up fame because of lower energy utilization and decreased contamination. Be that as it may, because of the inadmissible battery limit and unwavering quality, the EVs are not utilized properly.

At the point when a vehicle is driven on any road surfaces it encounters shocks because of the anomalies on the road. A suspension system is introduced in a vehicle to damp the relative movement between the wheels and body of the vehicle and give better handling and comfort to the travelers. For the most part, a conventional suspension system contains a curl of spring and a damper. A damper is gadget which changes over the vibrations into heat and disperses it to the encompassing. This disseminated heat energy originates from the fuel energy of the vehicle. Thus, a lot of fuel energy is wasted.

This lost energy can be recouped utilizing a regenerative shock absorber. A regenerative shock absorber is a device which can adequately weaken the shocks experienced by the vehicles and rather scattering the active energy from the shocks into dissipating heat energy, its damper converts it into helpful electrical energy. This valuable electrical energy can be put away in batteries for some time in the future. It can likewise be utilized to improve the damping ability of the shock absorber or to run the hardware of the vehicle to expand the eco-friendliness of the vehicle.

This paper has various sections, which review different researches on regenerative suspension system. The first section reviews the research done on the amount of energy that is dissipated from a moving vehicle. Then the next section reviews the potential of recovering the lost energy through the suspension system. The third section reviews the types and present state of research on regenerative shock absorbers.

\section{ENERGY DISSIPATION FROM VEHICLE}

The energy scattered from the vehicles is very critical in sum and we occasionally focus on this issue. As in [1], Out of the all-out fuel energy created by the motor of the vehicle just $10 \%$ to $16 \%$ of it is utilized for the portability of the vehicle. The rest is scattered in beating friction, suspension system and exhausts. What's more, significant piece of this energy is scattered through the suspension system.

In reference [2], inspected the impact of climb of road paths on the motion of the vehicle due energy loss in street scouring and suspension system. They exhibited that the authentic fuel ate up by the vehicles is more obvious than that appeared in the assessment places. They showed that the energy dispersal in a vehicle moving at $48 \mathrm{~km} / \mathrm{h}$ is from its suspension system is commonly $200 \mathrm{~W}$.

Another analyst, Browne [3], broke down the energy dispersal from the suspension system of the vehicle. It is discovered that from each shock absorbers of a vehicle running on parkway, roughly 40-60 Watts of power is disseminated.

In 2009, Yu [4], demonstrated that the energy dissipating from a vehicle isn't a direct result of pounding, it moreover depends upon the outside of the road, mass of the vehicle and speed. By using CARSIM diversion programming to and deduced that for a vehicle running on a class $\mathrm{C}$ road at a speed of $10 \mathrm{~m} / \mathrm{s}$ will around spread $42.3 \%$ of its fuel energy through its suspension system. Again in $2010 \mathrm{Yu}$ [5-6], thought about the regenerative suspension system. Using an entertainment, it was assumed that a vehicle running at $20 \mathrm{~m} / \mathrm{s}$ 
for 20 s scatters $651 \mathrm{~kJ}$ of energy through its suspension system.

From this investigation it might be contemplated that energy scattered from a vehicle doesn't simply depends upon the pounding yet furthermore depends upon the brutality of the road, mass of the vehicle and its speed. Moreover, that a significant proportion of energy is lost through the suspension system.

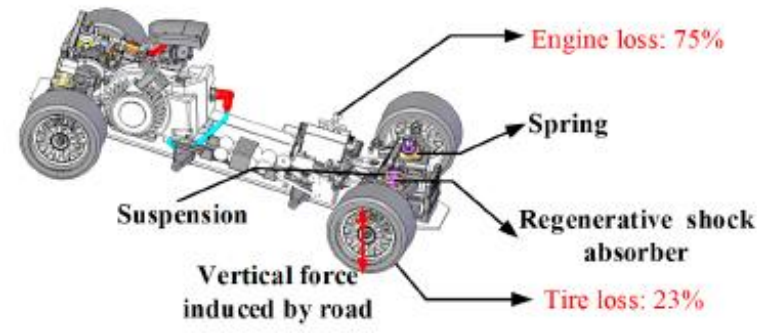

Figure 1. Energy dissipation from a vehicle

\section{ENERGY RECOVERING POTENTIAL OF REGENERATIVE SHOCK ABSORBER}

Presently the inquiry emerges about the recuperating capability of regenerative shock absorber. What amount of energy can be recuperated utilizing it? As per reference [7], the energy recuperated from the recovery procedure is sufficient to satisfy the energy necessity of an electromagnetic dynamic suspension, making it a selfcontrolled suspension system. Another analyst Hsu [8], assessed that for a fair size vehicle, the regenerative system can recoup about $100 \mathrm{~W}$ of intensity per wheel on interstate and roughly $400 \mathrm{~W}$ of energy can be recuperated at the paces of $96 \mathrm{~km} / \mathrm{h}$. In another exploration done by Kawamoto [9], demonstrated that roughly $15.3 \mathrm{~W}$ of energy can be recuperated from every one of the damper of a vehicle running at a speed of $80 \mathrm{~km} / \mathrm{h}$ on a class $\mathrm{C}$ street.

Zhang [10], found that for a vehicle moving at a speed of $30 \mathrm{~km} / \mathrm{h}$ on Class A, B, C, D and E streets, the recoverable force from the vehicle is roughly $2.07 \mathrm{~W}, 8.34 \mathrm{~W}, 33.33 \mathrm{~W}$, $133.39 \mathrm{~W}$ and $533.24 \mathrm{~W}$, separately.

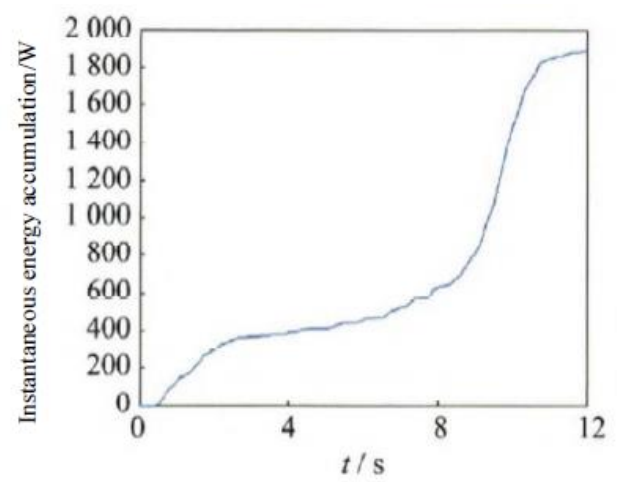

Figure 2. Gathering of Recoverable Energy after some time

As per reference [1], that by utilizing a regenerative suspension system in a vehicle, its eco-friendliness can be improved up to $10 \%$. These examines show that by utilizing regenerative suspension system, noteworthy measure of energy can be recouped, which can be utilized to control the dynamic suspension to improve its damping force or, it tends to be utilized to ru other electronic part of the vehicle to build its eco-friendliness.

\section{REVIEW OF THE PRESENT STATE OF TECHNOLOGY}

The following figure shows the basic mechanism of how the dissipated energy can be recovered by using a regenerative shock absorber. Basically, three things are expected from a regenerative shock absorber that, it provides ride comfort, driving safety and efficient power recovery.

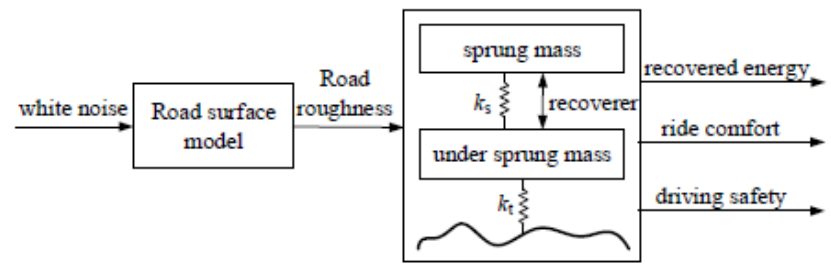

Figure 3. Basic model of regeneration of energy from vehicle suspension

The investigation on recouping the active energy lost through the vehicle suspension system is continuing for over three decades. There are a wide range of standards and structures of regenerative shock absorbers are available dependent on crafted by numerous analysts. In view of the energy change system instrument, the above system can be named:

A. Regenerative Shock Absorber utilizing a Linear Generator

This is the easiest structure for a regenerative shock absorber. It comprises of a magnet gathering and a loop get together, mounted on different sides of the shock absorber. At the point when a shock is applied to the vehicle there is a relative movement between the magnets and the curl. Because of this relative movement the an emf contradicting the movement of the shock absorber is produced. Because of which the shock experienced by the vehicle gets damped [11]-[12].

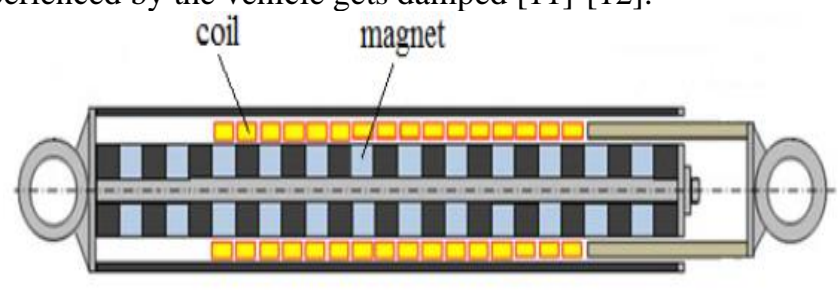

Figure 4. Linear regenerative shock absorber.

In any case, the issue with this configuration is that they are either too huge to even think about fitting inside the vehicle or can't give enough damping power. In the shock absorber planned in reference [11] the shock absorber is sufficiently little to fit inside the vehicle, yet it can just give a damping coefficient of $940 \mathrm{~N} . \mathrm{s} / \mathrm{m}$ in hamper. Another plan of the shock absorber is available in the reference [12]. This structure has a damping coefficient of $1350 \mathrm{~N} . \mathrm{s} / \mathrm{m}$, yet it is twice as extensive as the typical shock absorber utilized in the vehicles. As appeared in Fig.5. the Bose organization [13] utilized the linear electromagnetic suspension system in vehicle suspension. They discovered that the suspension system just uses $33 \%$ of the energy utilized by the vehicle's forced air system. 


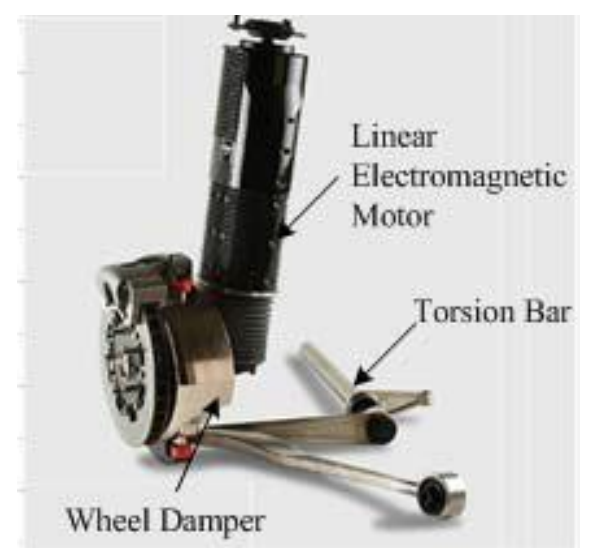

Figure 5. Straight Electromagnetic Suspension System created by Bose

\section{B. Regenerative Shock Absorber utilizing Rotary Mechanism}

The issue with the linear generator was with its size. The benefit of utilizing a rotating generator is that it is savvy and smaller in size. For instance, a straight marine wave energy converter introduced in reference [14] has a mass of about $1800 \mathrm{~kg}$ with measurements $3.3 \mathrm{~m} \times 1.3 \mathrm{~m}$ and produces an intensity of $1 \mathrm{~kW}$. While a turning machine furnished with a high gear apportion in reference [15], is about $1 \%$ in volume and mass, when contrasted with straight machine detailed in [14]. Hence, utilizing a revolving plan for the regenerative shock absorber will help us in structuring a productive and smaller damper. We should figure out how to change over the direct response of the shocks into rotational movement of the generator. These revolving movement shock absorbers are additionally named follows:

\section{Rotary Regenerative Shock Absorber Using Hydraulic} System

At the point when vehicle moves, the shock experienced by the vehicle causes the pressure driven cylinder of the shock absorber respond. Utilizing reasonable pressure driven gear, the straight movement of the piston can be converted into rotating motion, which drives the rotating engine of the generator. The electromotive power produced by the engine weakens the shock experienced by the vehicle. Be that as it may, the issue with this structure is that it has moderate proficiency, little bit expensive due precision parts required [.16]- [17]

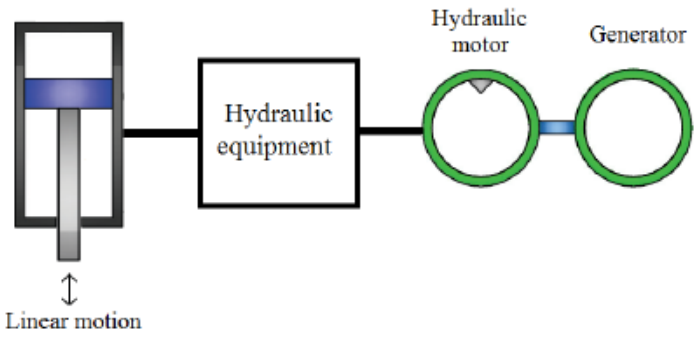

Figure 6. Regenerative shock absorber using hydraulic system

A hydraulic regenerative suspension system named GenShock created by Levant Power Corp. [18]. Fig.7. shows how GenShock functions.

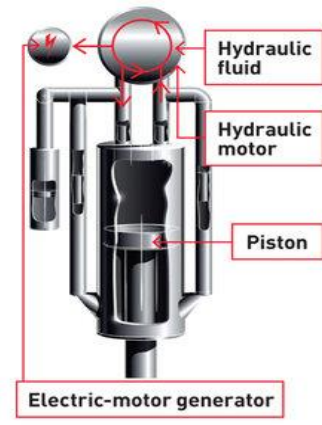

Figure 7. Hydraulic transmission regenerative shock absorber

It has a correcting instrument which guarantees that the engine of the generator moves just one way and considering this the productivity of the suspension system is improved. GenShock is intended to be utilized in military vehicles and it was asserted by Levant Force Corp. that this suspension system expands the productivity by $6 \%$.

\section{Ball Screw Mechanism}

In this sort of shock absorber, a ball screw is associated with the pole of the generator, and a nut is associated with the throwing of the damper. At the point when the vehicle encounters shock the nut has translational movement and goes here and there. The ball screw changes over this responding movement of the nut into rotating movement which drives the pole of the generator. The principle disadvantage of this system is that it comes up short at high frequencies and has impressive contact at low frequencies [19]- [20.]

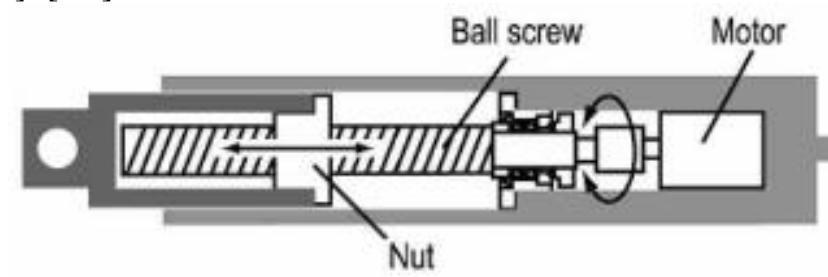

Figure 8. Regenerative shock absorber using a ball screw nut

As in [21], a regenerative shock absorber utilizing a twin pair ball screws have been produced for EVs. The straight damping coefficient of this shock absorber was determined to be $10,580 \mathrm{~N} . \mathrm{s} / \mathrm{m}$. The model had the option to produce a normal intensity of $3.701 \mathrm{~W}$ with top effectiveness of recuperating the vibration energy of $51.1 \%$ and normal proficiency of $36.44 \%$. The plan of the model is appeared in the Fig.9.

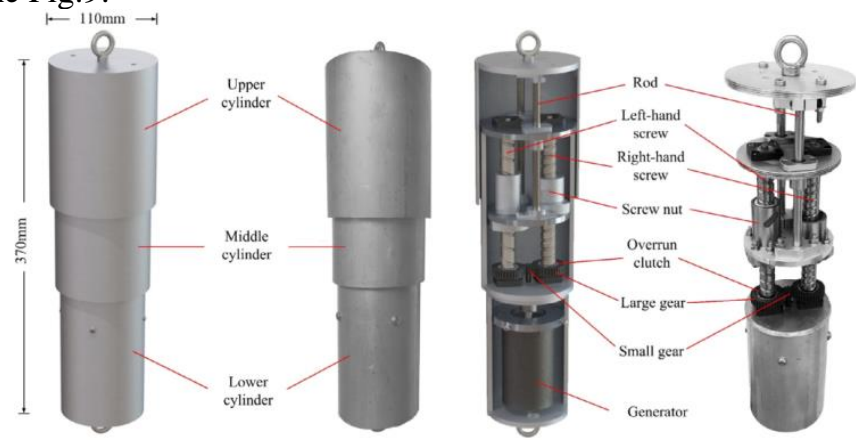

Figure 9. Structure of the twin ball screw regenerative shock absorber 


\section{Rack and Pinion Mechanism}

This sort of regenerative shock absorber utilizes rack-pinion, bevel gears, gearheads, and a generator. The rack-pinion is associated with the external cylinder and the generator is associated with the internal cylinder of the damper. When there is a relative movement between the inward and external cylinders, the rack drives the pinion, and this rotational movement of the pinion is moved to the pole of the generator by utilizing slope gears. Incline outfits likewise amplify the movement of the pinion. The Fig.10. shows the activity of this regenerative shock absorber.

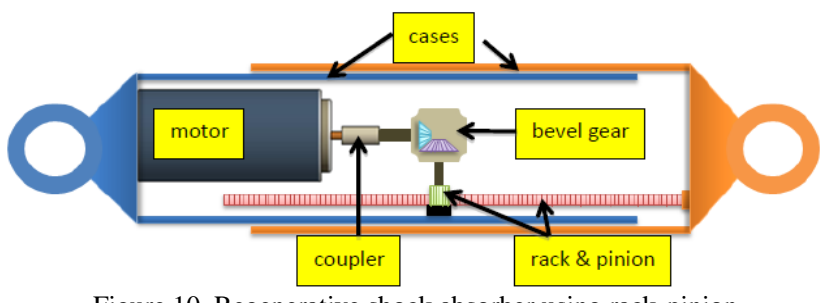

Figure 10. Regenerative shock absorber using rack-pinion

Using two roller holds the rotational movement can be made unidirectional. The segment is showed up in the Fig.9. underneath. The shortcoming of using this is the grinding among devices and using such an enormous number of parts makes its arrangement very complex.[22]-[23].

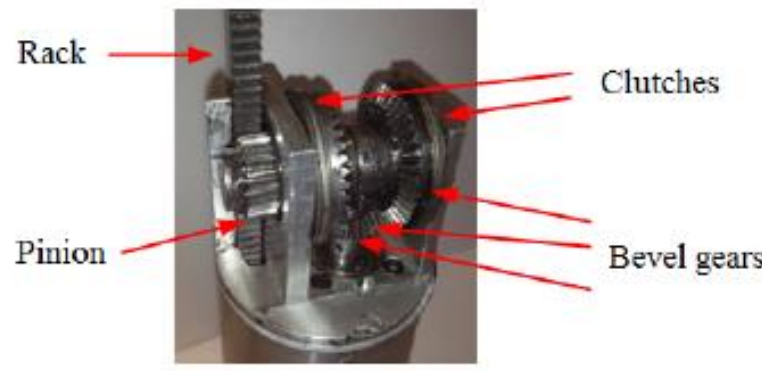

Figure 11. Unidirectional motion conversion mechanism

\section{Self-Powered Magnetorheological Suspension}

The magnetorheological (MR) damper has mechanical straightforwardness, high unique range, low force prerequisites, huge power limit and heartiness, due to which it has generally excellent shock retaining capacity. It was proposed in [24], it comprise of a MR damper and an electromagnetic acceptance gadget to assimilate the shocks. The EMI gadget ingests the shocks to produce electrical energy which controls the MR damper. In [25], a selfdetecting MR damper was introduced as appeared in Fig .12. In this structure, MR damper and force generator are coordinated into a natural entire and the voltages of touching loops with various stage are used to ascertain the relative speed.

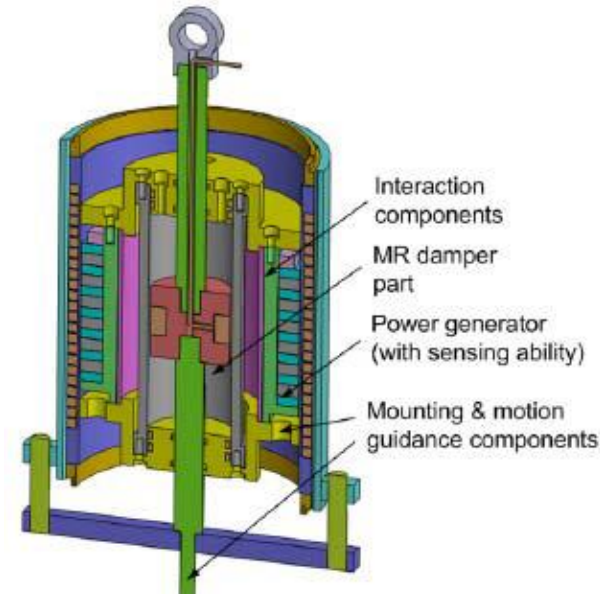

Figure 12. Self-sensing MR damper with power generation

\section{CONCLUSION}

Customary suspension systems disseminate active energy from the shocks as warmth to the encompassing and it is a significant wastage of energy. Also, significant piece of this wastage is through the suspension system. It was additionally discovered that the measure of recoverable energy relies upon the unpleasantness of the street surface, mass of the vehicle and its speed. In this paper different kinds of regenerative shock absorbers are inspected. What's more, by looking at their effectiveness, dependability and shock engrossing ability, hydraulic and self-detecting MR regenerative shock absorbers are the most encouraging ones. With further improvement in innovation the regenerative suspension system may supplant the customary suspension system in vehicles.

\section{FUTURE SCOPE}

The regenerative suspension is moderately another improvement and has a high degree for future upgrade. Numerous researchers have put forth the attempt to begin the improvement of regenerative suspension and bring this into consideration for various potential analysts. Being at its condition of early stages, regenerative suspension is certainly a sprouting point of research in the car business. It tends to be introduced in commercial vehicles, trucks and multi utility vehicles for invigorating the helper electrical parts. Such a framework will be considerably more viable in off-road and ATVs.

\section{ACKNOWLEDGEMENT:}

We thank to Director, Joint Director, Principal and HOD (ASGE) of Army Institute of Technology, Dighi ,Pune for providing us all the facilities, moral support and encouragement at this situation (pandemic of COVID-19) to complete this paper writing.

\section{REFERENCES}

[1] Pei S.Z., "Design of Electromagnetic Shock Absorbers for Energy Harvesting from Vehicle Suspensions", Master Degree Thesis, Stony Brook University, 2010.

[2] Segel L, Lu X P, "Vehicular Resistance to Motion as Influenced by Road roughness and Highway Alignment", Australian Road Research, 1982, 12(4), pp. 211-222. 
[3] Browne A, Hamburg J. On road measurement of the energy dissipated in automotive shock absorbers[C]//Symposium on Simulation and Control of Ground Vehicles Transport. Syst. 1986, 2: 167-186.

[4] Yu C, Wang W, Wang Q. Energy-saving Potential of EnergySuspension Suspension for Hybrid Vehicles [J]. Journal of Jilin University (Engineering), 2009, 39(4): 841-845.

[5] Yu F, Cao M, Zheng X. Feasibility Study of Energy Reactive Vehicle Active Suspension[J]. Journal of Vibration and Shock, 2005, 24(4):27-30.

[6] Yu F, Zhang Y. Regeneration Active Suspension Technology[J]. Journal of Agricultural Machinery, 2010, 41(1):1-6.

[7] Nakano K, Suda Y, et al., "Application of Combined Type Self Powered Active Suspensions to Rubber-tired Vehicles", JSAE Annual Congress, 2003, 6, pp. 19-22

[8] H su P, "Power recovery property of electrical active suspension systems", Proceedings of the Inter Society Energy Conversion Engineering Conference, Washington DC, USA: IEEE, 1996, pp. 1899-1 904.

[9] Kawamoto Y, Suda Y, Inoue H. Modeling of electromagnetic damper for automobile suspension[J]. Journal of System Design and Dynamics, 2007,1(3): 524-536

[10] Zhang W, Guo X, Fang Z. Experimental study on the energy recovery potential of energy-feed suspension [J]. Vibration, Test \& Diagnosis, 2015, 35(2): 225-230.

[11] X. Tang, T. Lin, and L. Zuo "Design and Optimization of a Tubular Linear Electromagnetic Vibration Energy Harvester," IEEE/ASME Transactions on Mechatronics, vol.19, no.2, pp. 615 $-622,2014$

[12] I. Martins, J. Esteves, G. D. Marques, and F. P. da Silva, "Permanent-magnets linear actuator applicability in automobile active suspensions," IEEE Transaction on vehicular technology., vol. 55 , no. 1 , pp. $86-94,2006$

[13] Jones W., "Easy ride: Bose Corp. Uses Speaker Technology to Give Ears Adaptive Suspension", IEEE Spectrum, 2005, 42(5): 12-14.

[14] J. Prudell, M. Stoddard, E.Amon, T. K. A. Brekken, and A. von Jouanne, "A permanent-magnet tubular linear generator for ocean wave energy conversion," IEEE Transactions on Industrial Applications, vol. 46, no. 6, pp. 23922400, 2010.
[15] CENTROID Servo Motor Dimensions. (2013, Jun.). [Online] Availabel: www.centroidenc.com/servo-dimensions.html

[16] X. Lin and G. Xuexun, "Hydraulic transmission electromagnetic energy-regenerative active suspension and its working principle," Int. Workshop on Intelligent Systems and Applications, pp. 1-5, 2010.

[17] Avadhany S, Abel P, tarasov V and Anderson Z, "Regenerative Shock Absorber," US Patent Specification 0260935.

[18] http://www.levantpower.com

[19] S. Liu, H. Wei, and W. Wang, "Investigation on some key issues of regenerative damper with rotary motor for automobile suspension," Interantional Conference on Electronic and Mechanical Engineering and Information Technology, pp. 14351439, Harbin, Heilongjiang, China, 2011.

[20] Song X, Li Z and Edmonson J, "Regenerative passive and semipassive suspension," US Patent Specification 7087342.

[21] Z. Wang, T. Zhang, Z. Zhang, Y. Yuan, and Y. Liu, "A highefficiency regenerative shock absorber considering twin ball screws transmissions for application in range-extended electric vehicles,"Available:

https://www.sciencedirect.com/science/article/pii/S187661021931 0781

[22] Z. Li , L. Zuo, J. Kuang, and G. Luhrs, "Energy -harvesting shock absorber with a mechanical motion rectifier," Journal of Smart Materials and Structures, vol.22, no. 5, pp. 2018-2025, 2007.

[23] Zhang, P. S., " Design of Electromagnetic Shock Absorber for Energy Harvesting from Vehicle Suspesions," MS thesis, Advisor L.Zuo, Stony Brook University, Stony Brook, NY.

[24] In-Ho Kim, Hyung-Jo Jung, and Jeong-Hoi Koo, "Experimental Evaluation of a Self-powered Smart Damping System in Reducing Vibrations of a Full-scale Stay Cable”, Smart Materials and Structures. 19(2010), pp.1-10.

[25] J.Q ZHANG, Z.Z PENG, J. YUE, et al. "Review of Regenerative Suspension Technology for Vehicle", Journal of Academy of Armored Force Engineering, 2012, 26(5), pp.1-7.(in Chinese) 